\title{
Enhancement of PC12 Neurite Extension via Plasma-Activated Medium by Nonthermal Atmospheric-Pressure Plasma-Bubbling System
}

\author{
Takanobu Haccho, ${ }^{\text {a,* }}$ Atsuru Kanno, ${ }^{a}$ Hiroshi Ichikawa, ${ }^{\mathrm{b}}$ Koji Yamamoto, ${ }^{\mathrm{c}}$ \\ Yusuke Morita, ${ }^{\mathrm{c}}$ \& Eiji Nakamachic \\ aGraduate School of Life and Medical Sciences, Doshisha University, Kyoto, Japan; 'Department \\ of Medical Life Systems, Doshisha University, Kyoto, Japan; 'Department of Biomedical \\ Engineering, Doshisha University, Kyoto, Japan \\ *Address all correspondence to: Takanobu Haccho, Graduate School of Life and Medical Sciences, Doshisha University, \\ 1-3 Tatara-Miyakodani, Kyotanabe, Kyoto, Japan, 610-0394; Tel.: + 81-80-5258-5254, E-mail: takaharry58@gmail.com
}

\begin{abstract}
In this study, an axonal extension enhancement system was developed using plasma-activated medium (PAM), which was generated through a nonthermal atmospheric-pressure plasma-bubbling system. Until recently, a number of regeneration methods for treatment of an injured central nervous system (CNS) have been proposed and examined. However, problems remain regarding quick recovery. It is also strongly required to establish an efficacious regeneration method for an injured CNS. Therefore, this study aimed to enhance the nerve axonal extension using PAM. The effectiveness of PAM in enhancing axonal extension was evaluated. First, the amounts of reactive species, such as $\mathrm{H}_{2} \mathrm{O}_{2}, \mathrm{NO}_{2}$, and $\mathrm{NO}_{3}$, in PAM were measured. Second, the stimulating effect of PAM was investigated by morphologically evaluating the PC12 cells after PAM stimulation. Experiments were conducted under 20 conditions to determine an optimal condition. Furthermore, the mechanism of enhancing PC12 neurite extension using PAM was elucidated. It was found that the $\mathrm{Ca}^{2+}$ concentration in PC12 cells was increased upon PAM stimulation and that Erk and CREB were activated, which enhanced the neurite extension. The results show that the PAM exhibited a selective cell-activation property for the treatment of CNS injuries.
\end{abstract}

KEY WORDS: PAM, plasma-bubbling system, PC12 cells, neurite extension

\section{INTRODUCTION}

In this study, we developed a system for enhancing neurite extension using plasmaactivated medium (PAM), which was generated through a bubbling-up process with nonthermal atmospheric-pressure plasma (NTAPP).

The central nervous system (CNS), which consists of the mammalian brain and spinal cord, is formed by nerve cells, astrocytes, and oligodendrocytes, and is an important system that transmits information throughout the body. It is difficult for the CNS to recover once it has been damaged in an accident, due to certain extrinsic and intrinsic factors. Exogenous factors include the presence of substances that inhibit axonal extension in the CNS and the low amount and type of neurotrophic factors induced by injury. The intrinsic factor is the decrease in the axonal extension of neurons with age. Due to these factors, the axons do not grow any further; hence, it becomes difficult for the CNS to recover its functions. 
The CNS regenerates in the following order: axonal extension, target site induction, synaptogenesis, and myelination. ${ }^{1}$ To treat a damaged CNS, research has been conducted with an aim to promote axonal extension, the first stage of regeneration. For example, the application of neurotrophic factors has been proposed and studied. ${ }^{2}$ Neurotrophic factor is a protein that is required for actions such as maintaining the survival of nerve cells and promoting neurite outgrowth and neurotransmitter synthesis. Neurotrophic factors include the nerve growth factor (NGF) and the brain-derived neurotrophic factor (BDNF). The NGF activates neurons by binding to Trk family high-affinity receptors and p75 lowaffinity receptors on the surface of target cells. It also plays an important role in regulating proliferation and differentiation of neurotransmitter neural stem cells. ${ }^{3,4}$ The damaged brain produces NGF to protect and repair nerve cells. Therefore, clinical application of NGF is important for the treatment of neurological diseases and the regeneration of nerve cells after nerve injury. However, neurotrophic factors such as NGF are high-molecularweight polypeptide molecules that are easily degraded in the body, cannot pass through the blood-brain barrier, and have side effects such as pain. ${ }^{5}$ Therefore, it is necessary to develop new, low-molecular-weight compounds that can promote differentiation of neurons and enhance the production and action of neurotrophic factors in vivo.

In this research, we focused on plasma medicine using NTAPP. NTAPP can be generated in an atmospheric environment. In addition, as the NTAPP temperature is similar to room temperature, it is possible to irradiate low-heat-resistance materials and living organisms with it and to apply it in medical fields. Plasma medicine has been reported to be effective in blood coagulation, ${ }^{6}$ brain edema suppression, ${ }^{7}$ and wound healing. ${ }^{8}$ In particular, the therapeutic effect of NTAPP is due to the reactive species it generates. In this study, we aim to promote axonal extension using NTAPP.

\section{MATERIALS AND METHODS}

\section{A. Plasma-Activated Medium Generation by Plasma-Bubbling System}

There are two ways of introducing the reactive species generated by NTAPP into a medium: direct irradiation and bubbling. In the direct-irradiation method, the reactive species generated in the gas phase are dissolved in the liquid phase (e.g., blood, body fluid, and culture fluid) and are allowed to interact. However, the reactive species simply remain on the surface of the liquid and hardly reach the cells. In addition, the reactive species are efficiently introduced into the liquid. Thus, in this study, a plasma-bubbling system was adopted. In this system, the reactive species can be diffused throughout the entire medium by introducing the former as bubbles. Furthermore, the attenuation of the reactive species by the surrounding air can be prevented by taking the plasma system out of contact with the air. By applying the bubbling method, the contact area between the bubbles and the medium increases. Thus, the plasma-bubbling system has been reported to increase the efficiency of the introduction of the reactive species to the target to about 20 times than that of the direct-plasma-irradiation system. This study used a damage-free multi-gas plasma jet (PCT-DFJM-01, Plasma Concept Tokyo Co., Ltd., Tokyo, Japan) $)^{9-11}$ 
that can steadily convert gases (e.g., $\mathrm{He}, \mathrm{Ar}, \mathrm{CO}_{2}$, and air) into plasma without damaging living organisms and cells (Fig. 1). Figure 2 shows the set-up for the generation of PAM using the plasma-bubbling system. To prevent the inflow of surrounding air and to achieve bubbling, a silicon tube was attached to the body of the container and was placed in a tank filled with water. The container was sealed with a polycarbonate lid.

\section{B. Reactive Species}

Dulbecco's modified eagle's medium (8456-65, Gibco, ThermoFisher Scientific, Waltham, MA) (DMEM) containing $0.05 \mu \mathrm{g} / \mathrm{mL}$ antibiotic (Antibiotic Antimycotic Solution, Stabilized, A5955, Sigma-Aldrich Japan Limited) was used as the solvent for the PAM. The NTAPP reacts with air and with various gases used for plasma generation to generate reactive species such as ions, radical species, and excited species. ${ }^{12}$ In the plasma-afterglow part, various reactive oxygen and reactive nitrogen species are generated by the interaction among the generated atoms, excited species, and the atmosphere.

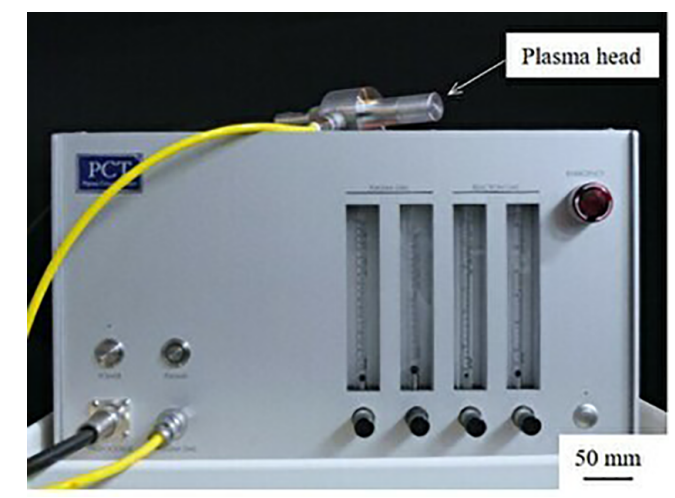

FIG. 1: Damage-free multi-gas plasma jet (PCT-DFJM-01)

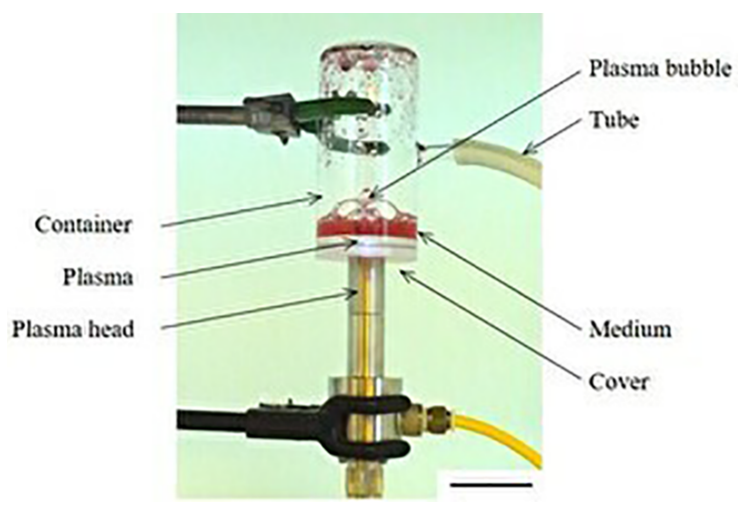

FIG. 2: Plasma-bubbling system (bar: $50 \mathrm{~mm}$ ) 
The afterglow part is where the ionizing gas exists after the external energy necessary for discharge is blocked. ${ }^{13}$ In this plasma-bubbling system, the influence of the atmosphere in the afterglow part was negligible as this part was not exposed to the ambient air. Air gas (atmospheric composition, Kist Co., Ltd., Kyoto, Japan) was used as a plasma source in this system, and the NTAPP-irradiated object was used as a medium. As most of the air is composed of nitrogen and oxygen, and the medium contains water, the reactive species produced include hydroxyl radical $(\cdot \mathrm{OH})$ and nitric oxide $(\mathrm{NO})$. Because $\cdot \mathrm{OH} \cdot$ and $\mathrm{NO}$ are highly reactive, they chemically react with nitrogen dioxide ion $\left(\mathrm{NO}_{2}^{-}\right)$, nitrogen trioxide ion $\left(\mathrm{NO}_{3}^{-}\right)$, and hydrogen peroxide $\left(\mathrm{H}_{2} \mathrm{O}_{2}\right) \cdot{ }^{14}$

It was confirmed that $\mathrm{NO}_{2}^{-}, \mathrm{NO}_{3}^{-}$, and $\mathrm{H}_{2} \mathrm{O}_{2}$, which can stably exist in the liquid phase, were generated mainly in the PAM. The amounts of $\mathrm{NO}_{2}^{-}, \mathrm{NO}_{3}^{-}$, and $\mathrm{H}_{2} \mathrm{O}_{2}$ produced, which were reactive species, were measured over time.

The reagent of the $\mathrm{NO}_{2} / \mathrm{NO}_{3}$ Assay Kit-CII (Colorimetric) Griess Reagent Kit (NK 05, Dojindo Laboratories Inc., Kumamoto, Japan) was used to measure the amounts of $\mathrm{NO}_{2}{ }^{-}$and $\mathrm{NO}_{3}{ }^{-}$in the PAM. The measurement was performed by mixing PAM and the reagent in a 96-well microplate (IWAKI). The absorbance at a wavelength of $540 \mathrm{~nm}$ was measured using a microplate reader (VientoXS, DS Farmer Biomedical Co., Ltd., Osaka, Japan).

The amount of $\mathrm{H}_{2} \mathrm{O}_{2}$ in the PAM was determined using the color reaction of xylenol orange (XO, $\mathrm{C}_{31} \mathrm{H}_{30} \mathrm{~N}_{2} \mathrm{Na}_{2} \mathrm{O}_{13} \mathrm{~S}$ ) caused by the oxidation of iron ions. ${ }^{15} \mathrm{H}_{2} \mathrm{O}_{2}$ changes iron (II) ion ( $\mathrm{Fe}^{2+}$ ) to iron (III) ion $\left(\mathrm{Fe}^{3+}\right)$ in acidic condition [Eqs. (1) and (2)]. Furthermore, $\mathrm{Fe}^{3+}$ reacts with $\mathrm{XO}$ to produce a dye complex $\left(\mathrm{Fe}^{3+}-\mathrm{XO}\right)$ with an absorption wavelength of around $560 \mathrm{~nm}$.

$$
\begin{gathered}
\mathrm{Fe}^{2+}+\mathrm{ROOH} \rightarrow \mathrm{Fe}^{3+}+\mathrm{OH}^{-}+\mathrm{RO} \\
\mathrm{Fe}^{2+}+\mathrm{H}_{2} \mathrm{O}_{2} \rightarrow \mathrm{Fe}^{3+}+\mathrm{OH}^{-}+\mathrm{OH}
\end{gathered}
$$

The XO solution used was composed of ammonium iron sulfate (II) hexahydrate (2.5 mM, 99.5\%; WDQ 3274, Wako Pure Chemical Industries, Ltd., Osaka, Japan), sulfuric acid (0.5 M; 32528-75, Nacalai Tesque, Inc., Kyoto, Japan), and XO (1.0 mM; 342-02953, Dojindo Laboratories Inc., Japan). The amount of each component was adjusted to obtain the desired concentration of the solution. As a measuring procedure, $2 \mathrm{~mL}$ of the XO solution and $2 \mathrm{~mL}$ of the PAM were mixed and allowed to stand for $40 \mathrm{~min}$ while being shielded from light. Then, $4 \mathrm{~mL}$ of the mixed solution was added to a glass cell, and the absorbance at a wavelength of $560 \mathrm{~nm}$ was measured using an ultraviolet-visible spectrophotometer (UV 2600, Shimadzu Corp., Kyoto, Japan).

\section{Cell Culture}

PC12 cells (RBRC-RCB0009, Lot No. 053, provided by RIKEN Cell Bank, Japan) were used for the neural model of this experiment. PC12 cells are derived from a transplantable 
rat adrenal pheochromocytoma, which respond to nerve growth factor by induction of neuronal phenotype. ${ }^{16} \mathrm{PC} 12$ cells were seeded in a $35 \mathrm{~mm}$ dish with cell density of $3 \times$ $10^{3}$ cells $/ \mathrm{cm}^{2}$. The DMEM medium, which was used as the culture medium, was supplemented with 10\% horse serum (16050-122, Gibco, ThermoFisher Scientific, Waltham, MA), 5\% fetal bovine serum (SH30396.03, HyClone Laboratories Inc., Logan, UT), and $0.05 \mu \mathrm{g} / \mathrm{mL}$ antibiotic. The PC12 cells in the culture medium were incubated for $24 \mathrm{~h}$ at $37^{\circ} \mathrm{C}$ and $5 \% \mathrm{CO}_{2}$.

\section{PAM Stimulation}

After incubation the culture medium was removed, and $2 \mathrm{~mL}$ of PAM prepared by the plasma-bubbling system and $50 \mathrm{ng} / \mathrm{mL}$ NGF (2.5S, 13,257-019, Gibco, ThermoFisher Scientific, Waltham, MA) were added to it. PC12 cells were stimulated in the PAM containing NGF in 1-, 2-, 3-, 4-, and 5-h incubators. After stimulation, the PAM was removed, and $2 \mathrm{~mL}$ of DMEM containing 10\% horse serum, $5 \%$ fetal bovine serum, 0.05 $\mu \mathrm{g} / \mathrm{mL}$ antibiotic, and $50 \mathrm{ng} / \mathrm{mL}$ NGF was added. The PAM was then incubated for $72 \mathrm{~h}$ from the start of PAM stimulation. To evaluate the effect of PAM stimulation on PC12 cells, the control group was cultured in $2 \mathrm{~mL}$ of DMEM containing $10 \%$ horse serum, $5 \%$ fetal bovine serum, $0.05 \mu \mathrm{g} / \mathrm{mL}$ antibiotic, and $50 \mathrm{ng} / \mathrm{mL}$ NGF. A schematic of the PAM stimulation process for PC12 cells is shown in Fig. 3. The conditions for preparing the PAM are shown in Table 1.

\section{E. PC12 Neurite Length Measurement}

PC12 cells were observed at $72 \mathrm{~h}$ using microscopy. Image ${ }^{17}$ was used to measure PC12 neurite length. Fifty cells were measured per dish. The measurement was conducted based on the following criteria: ${ }^{18}$

1. The cells should not be bound to other cells.

2. Only one neurite must be measured for each cell.

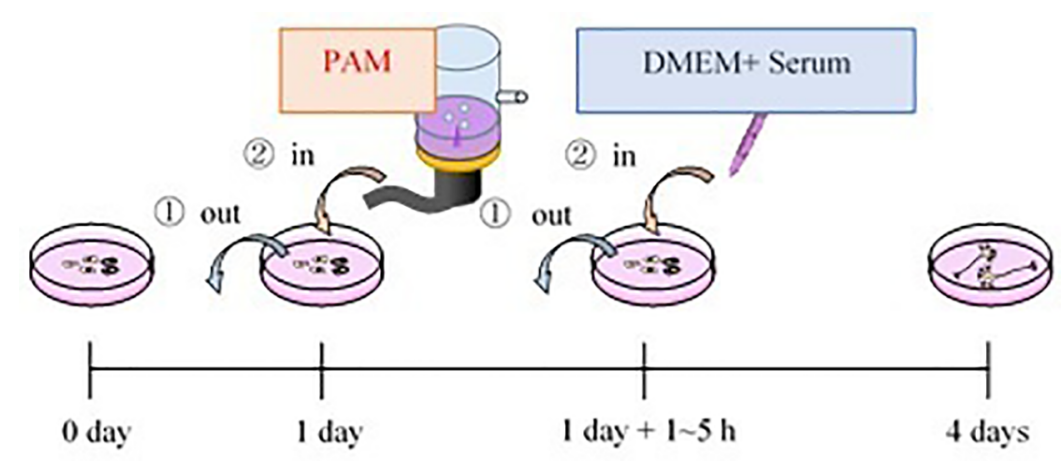

FIG. 3: Schematic of the PAM stimulation process for PC12 cells 
TABLE 1: Conditions for the preparation of PAM

\begin{tabular}{|c|c|}
\hline Plasma gas & Air (atmospheric composition) \\
\hline Flow rate & $3.0 \mathrm{~L} / \mathrm{min}$ \\
\hline Solvent & $\begin{array}{c}\text { DMEM containing } \\
0.05 \mu \mathrm{g} / \mathrm{mL} \text { antibiotic }\end{array}$ \\
\hline Volume & $20 \mathrm{~mL}$ \\
\hline Bubbling time & $15,30,45,60 \mathrm{~s}$ \\
\hline Voltage & $1.0 \mathrm{kV}$ \\
\hline Pulse repetition & $20 \mathrm{kHz}$ \\
\hline Nozzle diameter & $\phi 1.0 \mathrm{~mm}$ \\
\hline
\end{tabular}

3. If many nerve neurites extend from one cell, measure the longest one.

4. If the neurite is branched, select the longest path and set the sum of the distances in one direction as the neurite length.

\section{F. $\mathrm{Ca}^{2+}$ Imaging}

PC12 cells used as a neural model can stop cell proliferation when added with NGF. NGF is known as a typical inducer of neurite outgrowth in PC12 cells, and it is known that neurite outgrowth is promoted by $\mathrm{Ca}^{2+}$ influx into PC12 cells..$^{19,20}$ To verify the possibility that PAM stimulation is related to $\mathrm{Ca}^{2+}$ dynamics in PC12 cells, $\mathrm{Ca}^{2+}$ dynamics were visualized using Calcium Kit II-Fluo4 (Dojindo Laboratories Inc., Japan).

A $50 \mu$ dimethylsulfoxide was added to $50 \mu \mathrm{g}$ of $\mathrm{Ca}^{2+}$ fluorescent probe Fluo4-AM and was dissolved. Then $500 \mu \mathrm{L}$ of Hanks'HEPES Buffer $(10 \times), 160 \mu \mathrm{L}$ of $5 \times$ Pluronic F127 (or $5 \times$ Cremophor EL), and $100 \mu \mathrm{L}$ of $250 \mathrm{mmol} /$ Probenecid were added to 5 $\mathrm{mL}$ of Quenching buffer. Pure water (distilled water) was then added to make a total volume of $10 \mathrm{~mL}$. A $50 \mu \mathrm{L}$ Fluo4-AM DMSO solution was added to make loading buffer. A cell suspension of PC12 cells was seeded at a seeding density of $3.0 \times 10^{3}$ cells $/ \mathrm{cm}^{2}$ in a $35 \mathrm{~mm}$ dish (AGC Techno Glass Co., Ltd, Japan) and cultured for $1 \mathrm{~d}$ in an incubator at $37^{\circ} \mathrm{C}, 100 \%$ humidity, and $5 \% \mathrm{CO}_{2}$. The culture medium was DMEM containing $10 \%$ horse serum, $5 \%$ fetal bovine serum, and $0.05 \mu \mathrm{g} / \mathrm{mL}$ antibiotics. After incubation, the culture solution was removed, and a total of $2 \mathrm{~mL}$ of a mixture of DMEM and loading buffers containing $0.05 \mu \mathrm{g} / \mathrm{mL}$ antibiotics was added to obtain a 4:1 ratio. After addition, Fluo 4 was introduced into the cells by incubating for $30 \mathrm{~min}$. PC12 cells were irradiated with light at around $488 \mathrm{~nm}$; the excitation wavelength of Fluo 4 and the emitted light were determined by a confocal laser microscope (TCSSP 8 Multi-Photon, Leica). After $30 \mathrm{~s}, 1 \mathrm{~mL}$ of serum-free culture medium containing 50 $\mathrm{ng} / \mathrm{mL}$ of NGF or PAM was added. Fluorescence observation was performed for 10 min with an imaging interval of $1 \mathrm{~s}$ using an image analysis system software Leica Application Suite X (LAS X, Leica Microsystems). Luminance values were measured 
using a free image processing software ImageJ. However, the evaluation targets were single cells that were not connected to other cells and those that did not float and adhere.

\section{G. Western Blotting Analysis}

PC12 cells were seeded at a seeding density of $3.0 \times 10^{3}$ cells $/ \mathrm{cm}^{2}$ in a $100 \mathrm{~mm}$ dish (AGC Techno Glass Co., Ltd., Japan) and incubated for $1 \mathrm{~d}$ at $37^{\circ} \mathrm{C}, 100 \%$ humidity, and $5 \% \mathrm{CO}_{2}$. The culture medium was DMEM containing $10 \%$ horse serum, $5 \%$ fetal bovine serum, and $0.05 \mu \mathrm{g} / \mathrm{mL}$ antibiotics. After incubation, the culture solution was removed and stimulated by PAM (bubbling time $18 \mathrm{~s}$ ) for $10 \mathrm{~min}$. Cells were homogenized by scraper at $4^{\circ} \mathrm{C}$ in lysis buffer $(1.0 \mathrm{M}$ Tris- $\mathrm{HCl} \mathrm{pH} \mathrm{7.4,} 0.5 \mathrm{M}$ EDTA, 10\% NP-40, and $150 \mathrm{M}$ sodium chloride solution) containing protease inhibitor cocktail EDTA-free (ThermoFisher Scientific, Waltham, MA) and PhosSTOP (Roche Diagnostics, Basel, Switzerland). Lysates were centrifuged at $16000 \times \mathrm{g}$ at $4^{\circ} \mathrm{C}$, and the supernatant was collected. This procedure was repeated two times. Proteins in the lysates were separated by sodium dodecyl sulfate-polyacrylamide gel electrophoresis (SDS-PAGE) (BioRad Lab., Inc., Hercules, CA) and transferred to a polyvinylidene difluoride (PVDF) membrane (Sigma Aldrich, Darmstadt, Germany). The membrane was blocked at room temperature for $30 \mathrm{~min}$ using Tris-buffered saline (TBS) containing $2 \%$ bovine serum albumin (BSA) (Nacalai Tesque Inc., Japan) and 0.05\% Tween 20.

Anti-phospho-Erk1/2 (Thr202/Tyr204; 1:1000 dilution), anti-Erk1/2 (1:1000 dilution), anti-phospho-p38 (Thr180/Tyr182, 1:500 dilution), anti-phospho-CREB (Ser133, 1:1000 dilution), and anti- $\beta$-actin (1:500 dilution) (Cell Signaling Technology Inc., Danvers, MA) were used as primary antibodies (host species for all primary antibodies was rabbit.). Each blotted membrane was incubated with the antibody precisely diluted with $2 \%$ BSA- $0.05 \%$ Tween $20 /$ TBS overnight at $4{ }^{\circ} \mathrm{C}$.

After washing the membranes with $0.05 \%$ Tween 20 /TBS (TBST), they were subsequently incubated with a secondary antibody, a horseradish peroxidase-conjugated antirabbit immunoglobulin G (IgG) (Cell Signaling Technology Inc., Danvers, MA)" for 1 $\mathrm{h}$ at room temperature. Protein signals were detected using the ECL Plus (ThermoFisher Scientific, Waltham, MA) and imprinted on X-ray film (Fujifilm Corp., Japan).

\section{H. Statistical Analysis}

The Shapiro-Wilk test was performed as a test for normality. The median and average values of PC12 cell neurite length according to the difference in the PAM stimulation conditions shown in III B were calculated and shown in box and whisker plots. Steel test was used for multiple comparison test. At this time, the control group and the treatment group were used as separate stimulation condition group and one-sided tests were performed. Thereafter, the significance level $(0.05 / 20=0.0025)$ adjusted by the Bonferroni method was determined, and the value of the significance level for each group was determined. The significance level was $P<.05$.

Volume 9, Issue 2, 2019 
The median and average values of PC12 cell neurite length in the experiments using the PAM prepared under the optimum conditions were calculated and shown in box and whisker plots shown in III C. In addition, the effect of promoting PC12 cell neurite outgrowth was evaluated using the Mann-Whitney $U$-test. The significance level was $P$ $<.05$.

In the PC12 intracellular $\mathrm{Ca}^{2+}$ imaging using PAM shown in III D, the brightness increase rate at $60 \mathrm{~s}$ from the start of observation was calculated as an average value \pm standard error, and was presented in a bar graph. In addition, the increase of $\mathrm{Ca}^{2+}$ in PC12 cells was evaluated using the student $t$-test. The significance level was $P<.05$.

In the WB evaluation described in III $E$, the relative levels of p-Erk/Erk and $\mathrm{p}$-CREB $/ \beta$-actin were calculated as mean values \pm standard deviations and was shown in bar graphs. In addition, the rise of each relative level was evaluated using the student $t$-test. The significance level used was $P<.05$.

\section{RESULTS AND DISCUSSION}

\section{A. Reactive Species Measurement}

As shown in Fig. 2, plasma generation from plasma light emission in the culture medium was confirmed. It was also confirmed that plasma bubbles generated from the plasma device were diffused throughout the PAM. The reactive species generated by this system were superoxide, $\cdot \mathrm{OH}, \mathrm{NO}$, and other short-lived (lasted a few minutes) and long-lived (lasted several hours) reactive species such as $\mathrm{NO}_{2}^{-}, \mathrm{NO}_{3}^{-}$, and $\mathrm{H}_{2} \mathrm{O}_{2}$. It has also been reported that mitogen-activated protein kinase was activated by reactive oxygen in PC12 cells and that neurite extension had occurred..$^{21}$ Furthermore, it was found that cells were activated by oxidative stress by a spin trapping agent and that neurite extension was accelerated. ${ }^{22} \mathrm{NO}_{2}^{-}, \mathrm{NO}_{3}^{-}$, and $\mathrm{H}_{2} \mathrm{O}_{2}$, which can stably exist in the liquid phase as reactive species introduced in PAM, were measured. Figure 4 shows the amounts of $\mathrm{NO}_{2}^{-}(\mathrm{N}=$ $3), \mathrm{NO}_{3}^{-}(\mathrm{N}=3)$, and $\mathrm{H}_{2} \mathrm{O}_{2}(\mathrm{~N}=5)$ produced against bubbling time, where $\mathrm{N}$ indicates

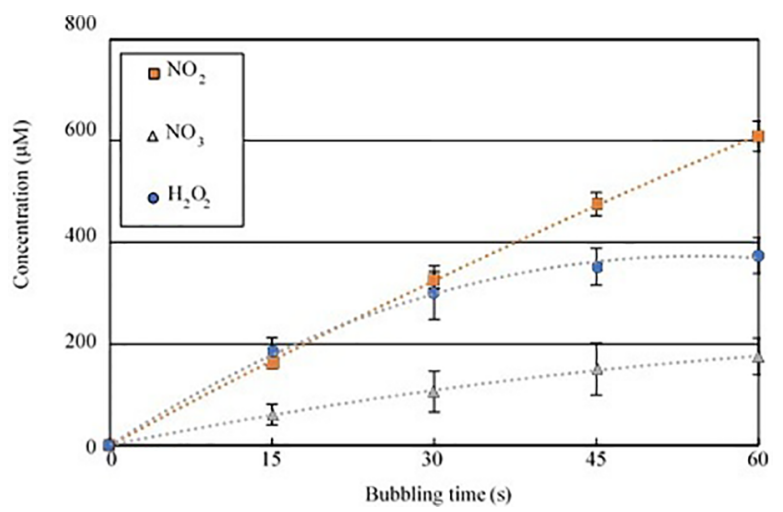

FIG. 4: Production amount of $\mathrm{NO}_{2}(\mathrm{~N}=3), \mathrm{NO}_{3}(\mathrm{~N}=3)$, and $\mathrm{H}_{2} \mathrm{O}_{2}(\mathrm{~N}=5)$ in $\mathrm{PAM}(\mathrm{mean} \pm \mathrm{SD})$ 
the number of measurements. Figure 4 shows that the reactive species $\mathrm{NO}_{2}^{-}, \mathrm{NO}_{3}^{-}$, and $\mathrm{H}_{2} \mathrm{O}_{2}$ were produced in the PAM by the plasma bubbled up system. Furthermore, the amount of each reactive species increased with increasing bubbling time. As the bubbling time increased, the amount of $\mathrm{NO}_{2}^{-}$produced increased linearly. However, the $\mathrm{H}_{2} \mathrm{O}_{2}$ amounts only increased about 1.1 times for the change in bubbling time from 45 to $60 \mathrm{~s}$. This indicates that a saturation point existed for $\mathrm{H}_{2} \mathrm{O}_{2}$ produced in the PAM. This could be due to the ultraviolet rays generated when the air used as the plasma source has turned into plasma. It has been reported that when $\mathrm{H}_{2} \mathrm{O}_{2}$ was irradiated with ultraviolet light, it decomposed into $\cdot \mathrm{OH}^{23}$ The decomposition of $\mathrm{H}_{2} \mathrm{O}_{2}$ by ultraviolet rays might have been performed with increasing bubbling time. Hence, the fabrication of the plasma-bubbling system in this study was successful because the reactive species $\mathrm{NO}_{2}^{-}$, $\mathrm{NO}_{3}^{-}$, and $\mathrm{H}_{2} \mathrm{O}_{2}$ were produced in the PAM made by this system.

\section{B. Morphological Evaluation of Neurite Extension}

Figure 5 shows the results of PC 12 cells observed $72 \mathrm{~h}$ after the start of PAM stimulation with the control group. Figure 6 shows the neurite length at $72 \mathrm{~h}$ from the start of PAM stimulation and the significant difference from the statistical analysis. The experimental conditions were all 20 combinations of stimulation time $(1,2,3,4$, and $5 \mathrm{~h})$, bubbling time $(15,30,45$, and $60 \mathrm{~s})(\mathrm{N}=150)$, and one control $(\mathrm{N}=150)$, which resulted in a total of 21 conditions. In this case, $\mathrm{N}$ represents the number of neurites measured according to the neurite length measurement protocol. As shown in Fig. 6, it was found that the PC12 cell neurite length tended to be longer compared to that of the control group for all conditions other than the $60 \mathrm{~s}$ bubbling time and 4- and 5-h stimulation

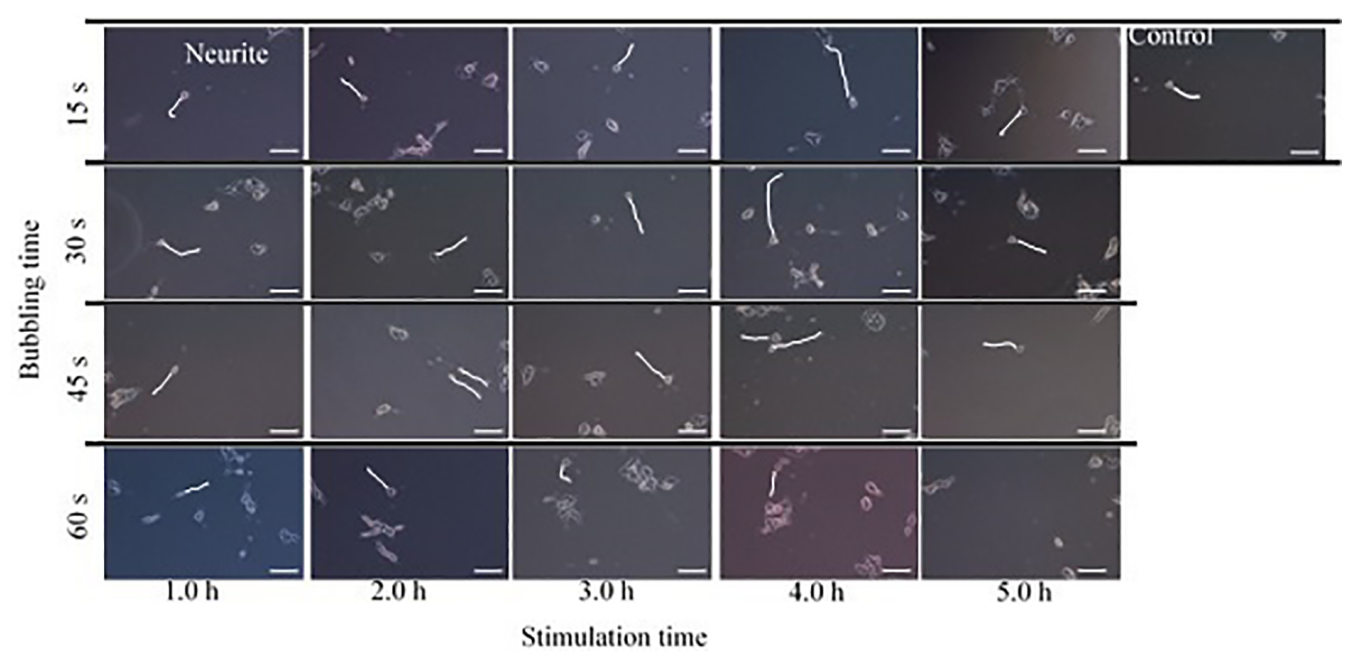

FIG. 5: Images of microscopic observation of PC12 cells $72 \mathrm{~h}$ after the start of PAM stimulation (bar: $100 \mu \mathrm{m}$ )

Volume 9, Issue 2, 2019 


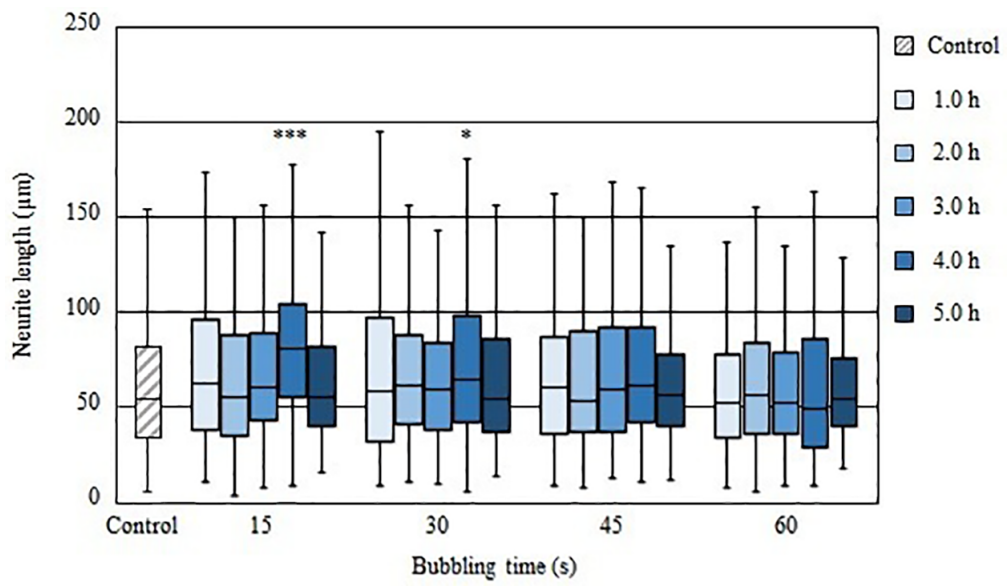

FIG. 6: Axonal length at $72 \mathrm{~h}$ after the start of PAM stimulation $\left(\mathrm{N}=150,{ }^{*} P<.05,{ }^{* * *} P<.001\right)$

times. Furthermore, in the 15-, 30-, and 45-s bubbling time groups, a stimulation time of $4 \mathrm{~h}$ tended to have the highest neurite extension in each bubbling time group. This confirms the significant neurite length in the control group under the 15-s bubbling time and 4-h stimulation time and the 30-s bubbling time, 4-h stimulation time. Therefore, the PAM had an effect on enhancing neurite extension on PC12 cells. Changes in the bubbling time affected the amount of reactive species generated in the PAM. Hence, it is presumed that neurite extension was enhanced by the interaction between the amount of reactive species and stimulation time. The PC12 cell neurite length was calculated.

It also shows the longest neurite length group (bubbling time $15 \mathrm{~s}$, stimulation time $4 \mathrm{~h}$ ) and the shortest neurite length group (bubbling time $60 \mathrm{~s}$, stimulation time $5 \mathrm{~h}$ ). The reactive species $\mathrm{NO}_{2}{ }^{-}, \mathrm{NO}_{3}^{-}$, and $\mathrm{H}_{2} \mathrm{O}_{2}$ produced in the PAM gave oxidative stress to the cells. Oxidative stress is generally known to have a negative effect on cells. In Fig. 6, the effect of enhancing neurite extension decreased for the 5-h stimulation time and 60-s bubbling time. The prolonged stimulation and excessive reactive species might have a negative effect on PC12 cells. However, positive effect on cells from moderate oxidative stresses has received attention in recent years. ${ }^{24}$ Therefore, long-lived reactive species $\mathrm{NO}_{2}^{-}, \mathrm{NO}_{3}^{-}$, and $\mathrm{H}_{2} \mathrm{O}_{2}$ generated in PAM that give oxidative stress to PC12 cells could enhance $\mathrm{PC} 12$ cell neurite extension.

\section{Selection of Optimum Conditions Using Response Surface Method}

The response surface method is an optimization method that uses an approximation of the objective function of the optimization problem and a response aspect function for the approximation. For the response surface method, the extended function program (RSMaker for Excel version 0.1) developed at Tokyo Institute of Technology was used as a macrofunction of Microsoft Excel. ${ }^{25}$ Figure 7 shows the response surface map. The response surface shows a mountain shape with the 15-s bubbling time and 4-h 


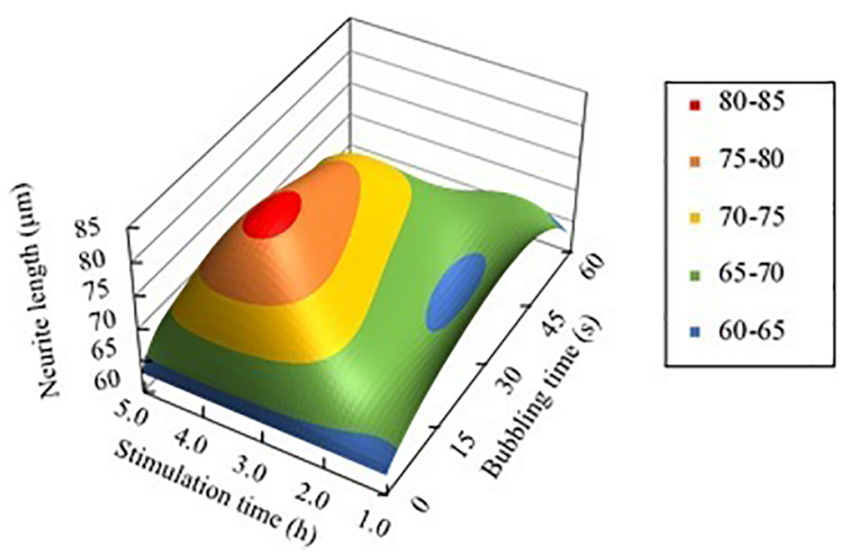

FIG. 7: Optimum condition search using the response surface method. The objective function is the neurite length, and the design variables are the bubbling time and the stimulation time.

stimulation time as the peak. In addition, the optimal conditions for enhancing the neurite extension of PC12 cells were the $3.9 \mathrm{~h}$ stimulation time and 18-s bubbling time.

The neurite extension-enhancing effect of each reactive species $\left(\mathrm{NO}_{2}^{-}, \mathrm{NO}_{3}^{-}\right.$, $\mathrm{H}_{2} \mathrm{O}_{2}$ ) was investigated. The explanatory variables were the three reactive species, and the target variable was the neurite length for the response surface method. Figure 8 shows the response surface map of the neurite length for each reactive species. It shows that brightness increased with the increasing length of the neurite; the spindleshaped figure shows a neurite length of about $80 \mu \mathrm{m}$. A neurite extension enhancement

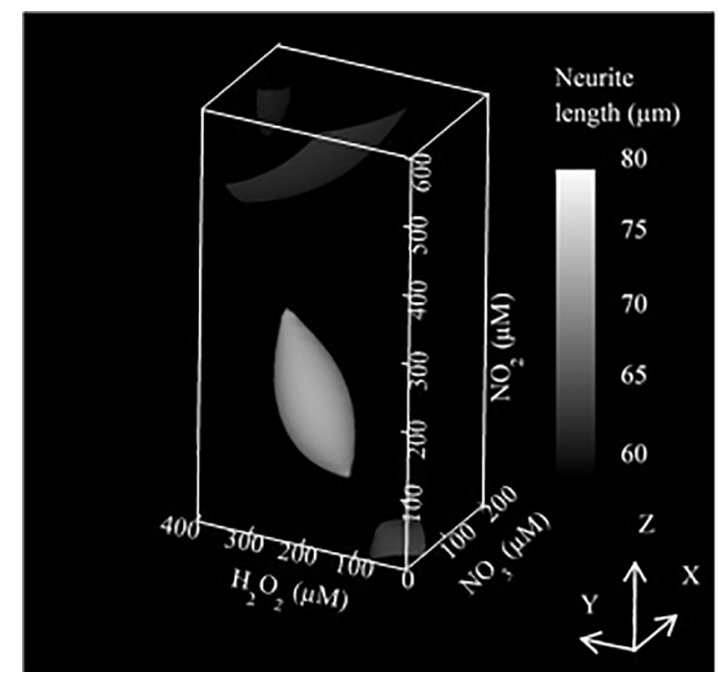

FIG. 8: Optimum amount of reactive species using response surface method 
effect was expected within the range of this figure (based on the amount of each reactive species). The ranges for the reactive species' effect are as follows: $100 \leq \mathrm{NO}_{2}^{-} \mu \mathrm{M}$ $\leq 300,37 \leq \mathrm{NO}_{3}{ }^{-} \mu \mathrm{M} \leq 103,150 \leq \mathrm{H}_{2} \mathrm{O}_{2} \mu \mathrm{M} \leq 300$. Furthermore, the closed curved surface indicates that an optimum amount for each reactive species existed. The optimum values were as follows: $200 \mu \mathrm{M}$ for $\mathrm{NO}_{2}^{-}, 70 \mu \mathrm{M}$ for $\mathrm{NO}_{3}^{-}$, and $188 \mu \mathrm{M}$ for $\mathrm{H}_{2} \mathrm{O}_{2}$.

Based on Fig. 7, PC12 cells were cultured under the optimum conditions (18-s bubbling time, 3.9-h stimulation time). The culturing procedure was carried out as indicated in the PAM stimulation condition. Figure 9 shows the neurite length of PC12 cells 72 $\mathrm{h}$ after the start of PAM stimulation. In Fig. 9, the PAM stimulation under the optimal conditions resulted in significant enhancement of the neurite extension of PC12 cells in the control group. As a result, it was presumed that the enhancement of neurite extension was caused by the coupling effects of $\mathrm{NO}_{2}^{-}, \mathrm{NO}_{3}^{-}$, and $\mathrm{H}_{2} \mathrm{O}_{2}$, the reactive species produced in PAM. Finally, it was confirmed that PAM exhibited a selective cell activation property for regeneration of CNS.

\section{Evaluation of $\mathrm{Ca}^{2+}$ Response by PAM}

Figure 10 shows the rate of change in luminance value with respect to time-dependent changes during control and PAM stimulation \pm standard error. Figure 11 shows fluorescence observation images at $0 \mathrm{~s}, 30 \mathrm{~s}$, and $60 \mathrm{~s}$ from the start of observation. The luminance value at the start of observation was $\mathrm{F}_{0}$, the luminance value at the start of observation $\mathrm{t} \mathrm{s}$ was $\mathrm{F}_{\mathrm{t}}$, and the $\mathrm{Ca}^{2+}$ response in each cell was evaluated as the luminance increase rate $\mathrm{F}_{\mathrm{t}} / \mathrm{F}_{0}$. From Fig. 10, an increase in the luminance ratio was found in both the control group and the PAM stimulation group within $30 \mathrm{~s}$ from the start of stimulation

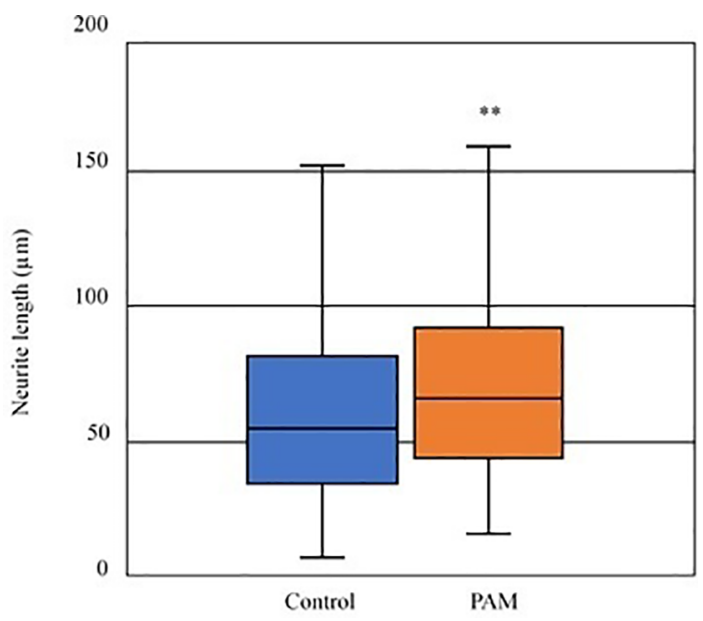

FIG. 9: The neurite length of PC12 cells at $72 \mathrm{~h}$ after the start of PAM stimulation (bubbling time $18 \mathrm{~s}$, stimulation time $3.9 \mathrm{~h})(\mathrm{N}=150, * * P<.01)$ 


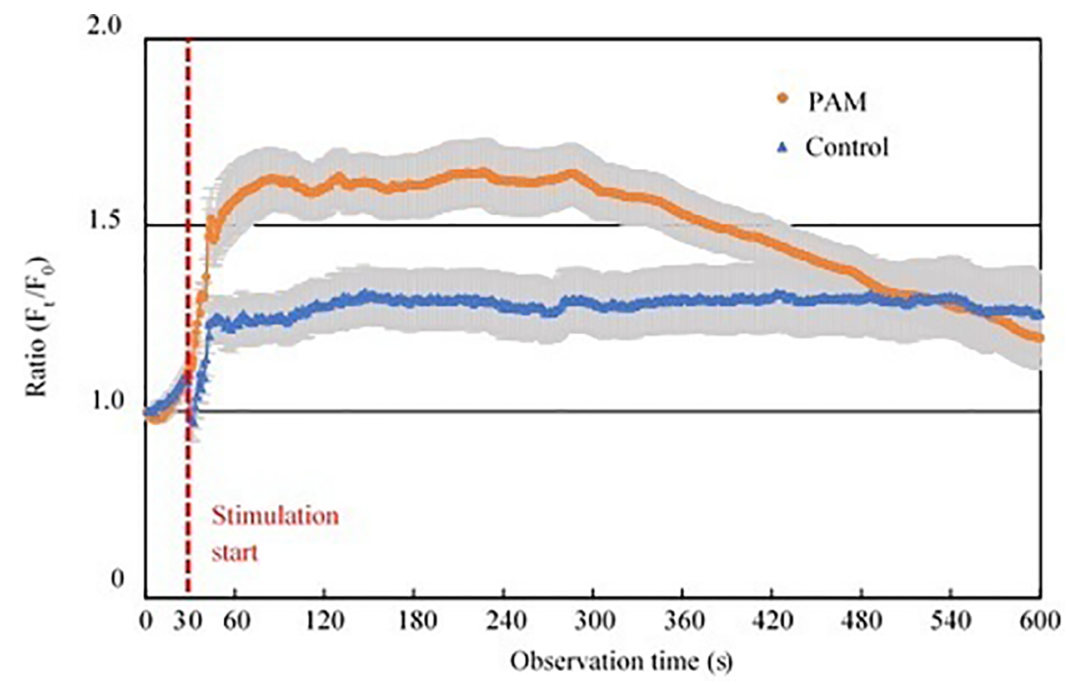

FIG. 10: Time history of luminance ratio, which evaluates the change of the intracellular $\mathrm{Ca}^{2+}$ concentration compared with the initial value

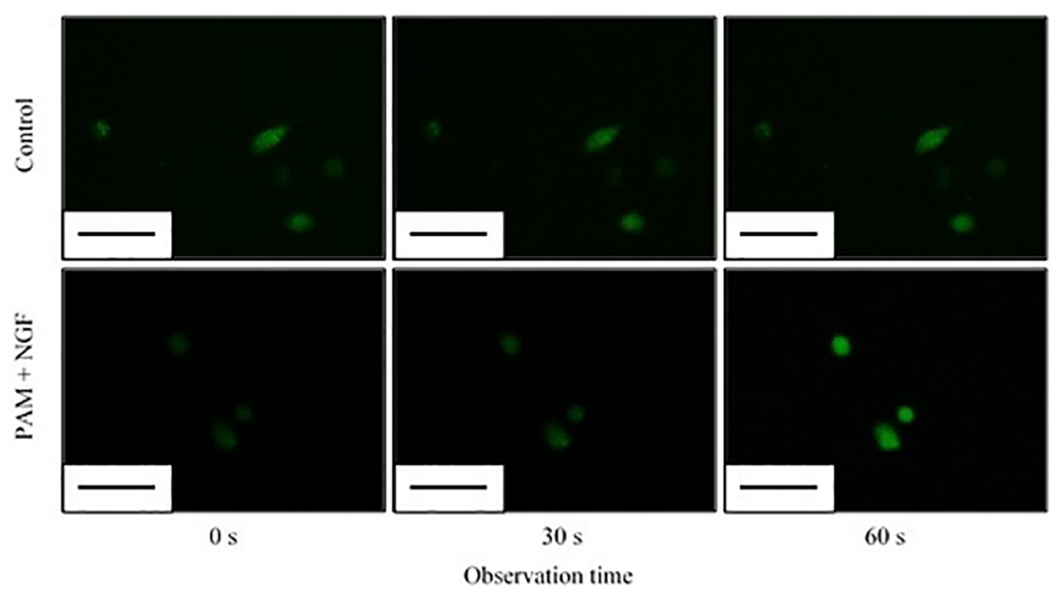

FIG. 11: Fluorescence observation images at $0 \mathrm{~s}, 30 \mathrm{~s}$, and $60 \mathrm{~s}$ from the start of observation (bar: $50 \mu \mathrm{m}$ )

(60 s from the start of observation). In the control group, after adding DMEM + NGF, the rate of change in luminance value increased to about 1.2 and remained constant until the end of observation. The brightness increase factor in the control group might be due to the stimulus at the time of addition. In the PAM stimulation group, after PAM + NGF was added, the rate of change in luminance increased to a maximum of about 1.6 , then decreased linearly $300 \mathrm{~s}$ after the start of stimulation ( $360 \mathrm{~s}$ from the start of 
observation) to about 1.1 at the end of observation. The value was close to the luminance value at the start of observation. Cell death was not confirmed from the cell condition at the end of the observation. This suggests that the decrease in luminance resulted in intracellular $\mathrm{Ca}^{2+}$ regulation. Figure 12 shows the change rate of luminance value \pm standard error at $30 \mathrm{~s}$ from the start of stimulation ( $60 \mathrm{~s}$ from the start of observation). In Fig. 12, the PAM stimulation group showed a significant increase in the change rate of the luminance value compared to the control group. Therefore, $\mathrm{Ca}^{2+}$ mobilization in PC12 cells occurred with PAM stimulation, and the intracellular $\mathrm{Ca}^{2+}$ concentration increased. This factor was presumed to be due to the combined effects of the active species $\mathrm{NO}_{2}, \mathrm{NO}_{3}$, and $\mathrm{H}_{2} \mathrm{O}_{2}$ present in the PAM produced by the system, as it is reported in the literature that the intracellular $\mathrm{Ca}^{2+}$ concentration can be increased by the active species. ${ }^{26}$ However, further studies are needed to determine whether the $\mathrm{Ca}^{2+}$ increase is extracellularly mediated by TRP channels or the like, or whether $\mathrm{Ca}^{2+}$ is released from the endoplasmic reticulum.

\section{E. Effects of PAM on MAPK/CREB Signaling Pathway in PC12 Cells}

NGF is a typical inducer in the neurite outgrowth of PC12 cells used in this experiment. NGF binds to TrkA of PC12 cells and activates MAPK including Erk, p38, and JNK canonical pathways. Among them, the activation of ERK and p38MAPK causes the activation of CREB, a transcription factor. It also causes the expression of genes necessary for neurite extension and the expression of proteins produced from these genes, which promotes neurite extension. ${ }^{27,28}$ Therefore, the activation of Erk, p38, and CREB was verified using Western blotting (WB).

Figure 13 shows WB results for Erk, phospho-Erk (p-Erk), phospho-p38 (p-p38), phospho-CREB (p-CREB), and $\beta$-actin. The subjects were PC12 cells 10 min after PAM stimulation (bubbling time $18 \mathrm{~s}$ ). The conditions were I: DMEM, II: DMEM + NGF, III: PAM, and IV: PAM + NGF. Bands of conditions II and IV were detected in p-Erk, p-CREB, and p-p38. From condition II, it was found that Erk, CREB, and p38 were

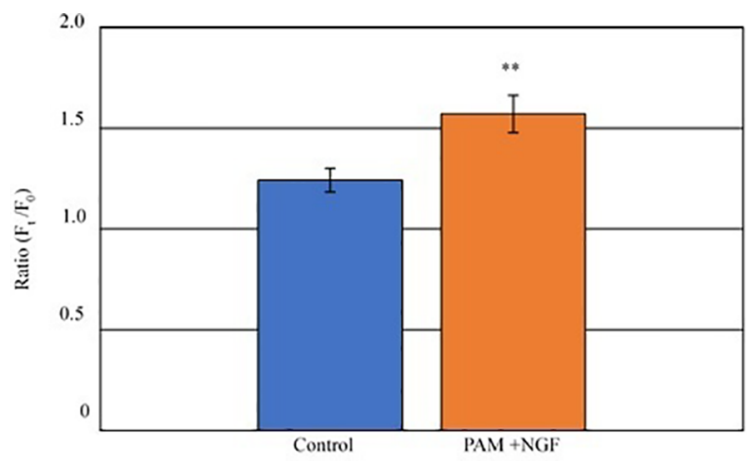

FIG. 12: Luminance ratio, which evaluates the change of intracellular $\mathrm{Ca}^{2+}$ concentration compared with the initial value at $60 \mathrm{~s}(\mathrm{~N}=20$, mean $\pm \mathrm{SE}, * * P<.01)$ 


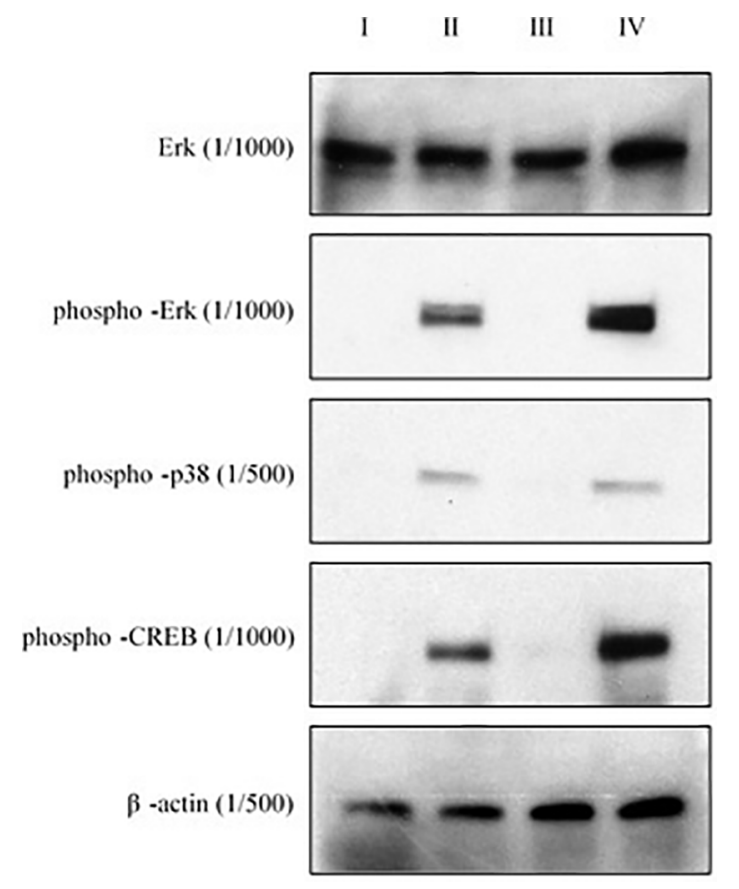

FIG. 13: Results of Western blotting. I, DMEM: II, DMEM + NGF: III, PAM; IV, PAM + NGF.

activated by NGF. p-p38 was not activated by PAM because it did not show any difference between conditions II and IV. However, in p-Erk and p-CREB, there was a difference in expression level between conditions II and IV. Densitometry was performed using ImageJ for Erk, p-Erk, p-CREB, and $\beta$-actin in Fig. 13.

Figures 14 and 15 show the relative levels of $p$-Erk/Erk and p-CREB/ $\beta$-actin, respectively. The relative level was obtained by dividing the values in all conditions by those in control II. In Figs. 14 and 15 respectively, p-Erk and p-CREB showed about 2.3-fold and about 2.6-fold expression of condition IV versus that of condition II, both of which were significantly increased. The results indicate that PAM promotes Erk and CREB activation, and that PAM promotes neurite extension via Erk and CREB. Furthermore, the expressions of $\mathrm{p}$-Erk and $\mathrm{p}$-CREB were not found under condition III, suggesting that PAM promotes the activation of Erk and CREB when NGF included in PAM. In other words, PAM seems to have enhanced the neurite extension effect of NGF. These results suggest that PAM is effective in promoting neurite extension.

It was mentioned in Section III D that $\mathrm{Ca}^{2+}$ concentrations in PC12 cells were increased by PAM. It was suspected that the increase of $\mathrm{Ca}^{2+}$ by PAM induced neurite extension through activation of Erk and CREB (Fig. 16). However, in this experiment, $\mathrm{Ca}^{2+}$ concentration was unknown for the pathway that leads to Erk activation after the increase of PC12 intracellular; hence, this could be a topic for future research. As a result, PAM could contribute to establishing new neurotherapy.

Volume 9, Issue 2, 2019 


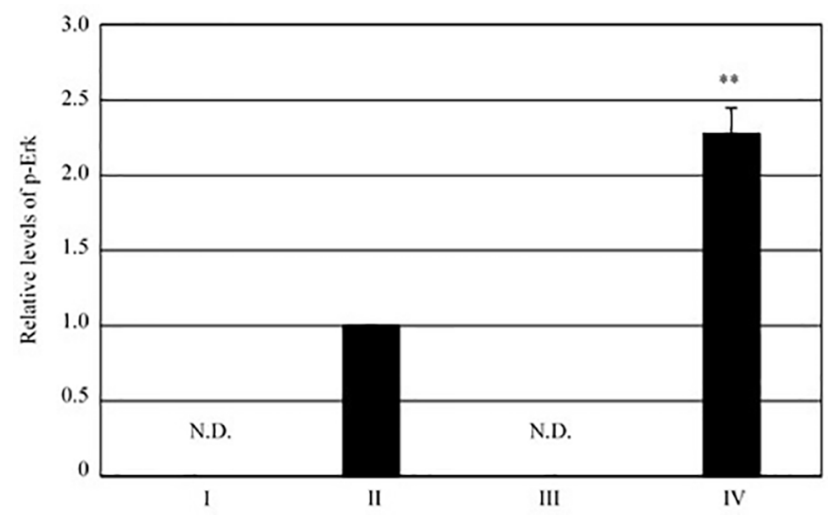

FIG. 14: Relative levels of p-Erk/Erk for control (condition II). I, DMEM; II, DMEM + NGF; III, PAM; IV, PAM + NGF ( $\mathrm{N}=3$, mean \pm SE, $* * P<.01$, N.D., not detected $)$.

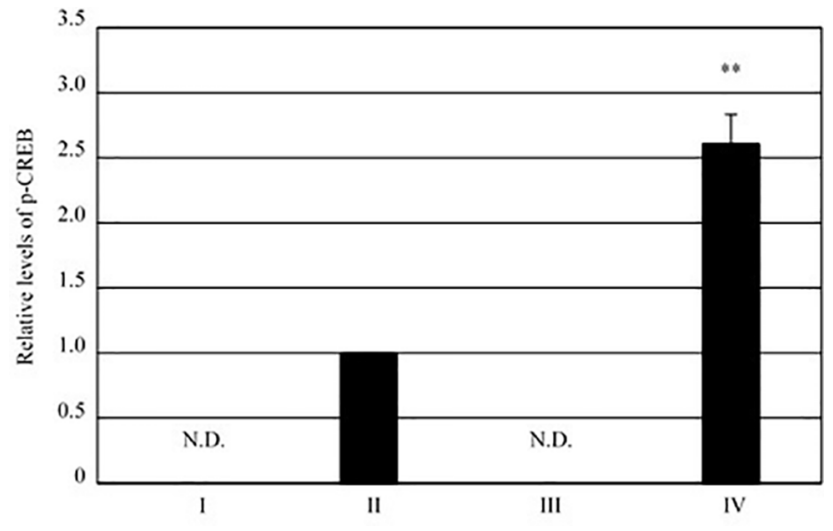

FIG. 15: Relative levels of $\mathrm{p}$-CREB/ $\beta$-actin for control (condition II). I, DMEM; II, DMEM + NGF; III, PAM; IV, PAM + NGF $\left(\mathrm{N}=3\right.$, mean $\pm \mathrm{SE},{ }^{* *} P<.01$, N.D., not detected $)$.

\section{CONCLUSION}

A system for enhancing neurite extension was developed using PAM, which was generated through a bubbling-up process with NTAPP. It was found that neurite extension was promoted by culturing PC12 cells in PAM. It was also observed that the reactive species $\mathrm{NO}_{2}, \mathrm{NO}_{3}$, and $\mathrm{H}_{2} \mathrm{O}_{2}$ were generated in the PAM produced by the system. The optimum reactive species concentrations were found to be $200 \mu \mathrm{M}$ for $\mathrm{NO}_{2}^{-}, 70 \mu \mathrm{M}$ for $\mathrm{NO}_{3}^{-}$, and $188 \mu \mathrm{M}$ for $\mathrm{H}_{2} \mathrm{O}_{2}$ by the response surface method. Furthermore, it was found that PAM, when used in combination with NGF, activated Erk and CREB and induced neurite extension promotion. Therefore, this system can be used as a new neurotherapy. 


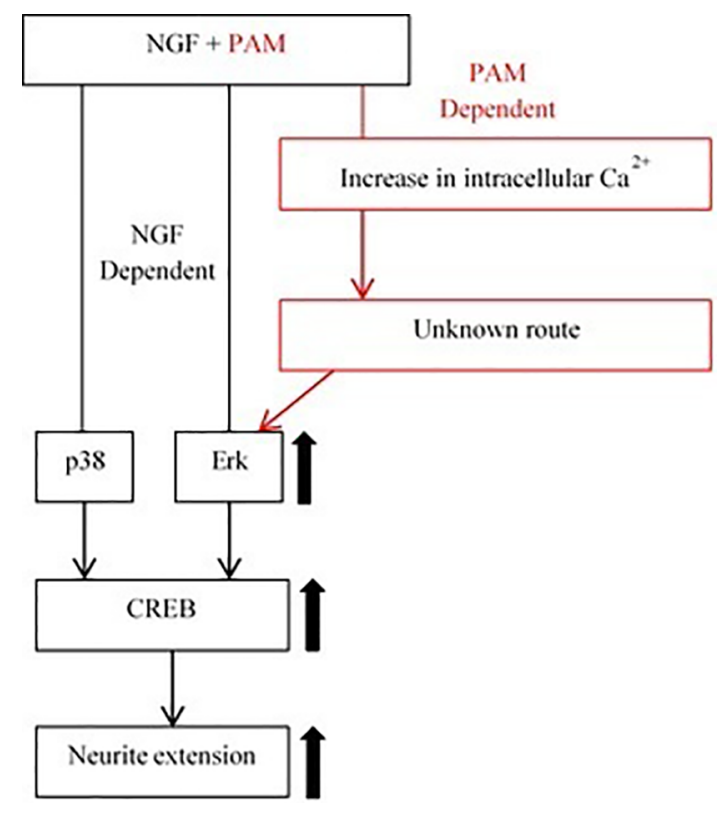

FIG. 16: Schematic diagram of the effect of PAM on the MAPK/CREB signaling pathway in PC12 cells

\section{ACKNOWLEDGMENT}

This work was financially supported by the Japan Society for the Promotion of Science (Grant-in-Aid for Scientific Research [B], Grant No. JP17H03150).

\section{REFERENCES}

1. Okano H, Ogawa Y, Nakamura M, Kaneko S, Iwanami A, Toyama Y. Transplantation of neural stem cells into the spinal cord after injury. Semin Cell Dev Biol. 2003;14(3):191-98.

2. Furukawa S. Basic research on neurotrophic factors and its application to medical uses. Yakugaky Zasshi. 2015;135(11):1213-26.

3. Wiesmann C, de Vos AM. Nerve growth factor: structure and function CMLS. Cell Mol Life Sci. 2001;58:748-59.

4. Huang JE, Reichardt FL. Trk receptors: roles in neuronal signal transduction. Annu Rev Biochem. 2003;72:609-42.

5. Svensson P, Carins BE, Wang K, Arendt-Nielsen L. Injection of nerve growth factor into human masseter muscle evokes long-lasting mechanical allodynia and hyperalgesia. Pain. 2003;104:241-47.

6. Fridman G, Friedman G, Gutsol A, Shekhter AB, Vasilets VN, Fridman A. Applied plasma medicine. Plasma Process Polym. 2008;5(6):503-33.

7. Kalghatagi S, Friedman G, Fridman A, ClyneAM. Endothelial cell proliferation is enhanced by low dose non-thermal plasma through fibroblast growth factor-2 release. Ann Biomed Eng. 2010;30(3):748-57.

8. Hirata T, Tsutsui C, Kanai T, Kudo Y, Iwashita M, Mori A. Tissue activation using atmospheric pressure plasma and its medical application. J Plasma Fusion Res. 2015;91(12):771-75.

Volume 9, Issue 2, 2019 
9. Okino A, Sasaki R, Nagata Y, Shigeta K, Iwai T, Miyahara H. Development and industrial applications of atomospheric multi-gas plasma sources. J Plasma Fusion Res. 2010;86:40-42.

10. Plasma Concept Tokyo, Inc [homepage on the Internet]. Tokyo: Plasma Concept Tokyo, Inc.; c2008[updated 2019 Nov 07; cited 2019 Nov 25]. Available from: http://www.pc-tokyo.co.jp/index.html.

11. Miyahara H, Shibata M, Oshita T, Takamatsu T, Okino A. Hydrophilization of polyimide film using damage-free multi-gas plasma jet. Chemical Engineers. 2013;39(4):372-77.

12. Takamatsu T, Uehara K, Sasaki Y, Miyahara H, Matsumura Y, Iwasawa A, Ito N, Azuma T, Kohno M, Okino A. Investigation of reactive species using various gas plasmas. RSC Adv. 2014;4:39901-05.

13. Kitano K, Taniguchi K, Sakai O, Takaki K, Namihara T, Hattori K. Let's obtain an atmospheric pressure plasma. Jpn Soc Plasma. 2008;84(1):19-28.

14. Ikuse K, Hamaguchi S. Numerical simulation for generation and transport of liquid-phase chemically reactive species that potentially trigger biological activities. Jpn Soc Plasma. 2015;91(12):780-84.

15. Jiang ZY, Woolard ACS, Wolff SP. Hydrogen peroxide production during experimental protein glycation. Fed Eur Biochem Soc. 1990;268(1):69-71.

16. Greene LA, Tischler AS. Establishment of a noradrenergic clonal line of rat adrenal pheochromocytoma cells which respond to nerve growth factor. Natl Acad Sci USA. 1976;73:2424-28.

17. Schneider CA, Rasband WS, Eliceiri KW. NIH image to imageJ: 25 years of image analysis. Nat Methods. 2012;9:671-75.

18. Nakamachi E, Matsumoto K, Sakiyama K, Yamamoto K, Morita Y. Enhancement of PC12 axonal extension via hybrid electromagnetic and mechanical stimulation. Jpn Soc Mech Eng. 2018;13(2):1-12.

19. Shibasaki K, Sugio S, Nagasawa M, Ishizaki Y, Kojima I. Transient receptor potential vanilloid 2 activation by focal mechanical stimulation requires interaction with the actin cytoskeleton and enhances growth cone motility. FASEB J. 2017;31(4):1368-81.

20. Boczek T, Ferenc B, Lisek M, Zylinska L. Regulation of GAP43/calmodulin complex formation via calcineurin-dependent mechanism in differentiated PC12 cells with altered PMCA isoforms composition. Mol Cell Biochem. 2015;407:251-62.

21. Katoh S, Mitsui Y, Kitani K, Suzuki T. Hyperoxia induces the neuronal differentiated phenotype of PC12 cells via a sustained activity of mitogen-activated protein kinase induced by Bcl-2. Biochem Soc. 1999;338(1):465-70.

22. Tsuji M, Inanami O, Kuwabara M. Induction of neurite outgrowth in PC12 cells by $\alpha$-phenyl-N-tertbutylnitron through activation of protein kinase $\mathrm{c}$ and the ras-extracellular signal-regulated kinase pathway. Biol Chem. 2001;276(35):32779-85.

23. Emoto I, Nakagawa S. Development of a cotton fabrics impurities decomposition process using the advanced oxidation method. Bulletin TIRI. 2016;(11):71-4.

24. Banno Y, Ohguchi K, Matsumoto N, Koda M, Ueda M, Hara A, Dikic I, Nozawa Y. Implication of phospholipase D2 in oxidant-induced phosphoinositide 3 kinase signaling via Pyk2 activation in PC12 cells. J Biol Chem. 2005;285:16319-24.

25. RSMaker for Excel [homepage on the Internet]. Tokyo: Akira Todoroki.; [updated 2009 Dec 21; cited 2019 Nov 25]. Available from: http://todoroki.arrow.jp/ssoft/RSMkaisetsu.pdf.

26. Sasaki S, Kanzaki M, Kaneko T. Calcium influx through TRP channels induced by short lived reactive species in plasma-irradiated solution. Sci Rep. 2016;6(25728):1-11.

27. Vaudry D, Stork PJ, Lazarovici P, Eiden LE. Signaling pathways for PC12 cell differentiation: making the right connections. Science. 2002;296(1):1648-49.

28. Chung J, Kubota H, Ozaki Y, Uda S, Kuroda S. Timing-dependent actions of NGF required for cell differentiation. PloS One. 2010;5(1):55. 